\title{
HORTA ESCOLAR: A EXTENSÃO DIALOGANDO COM A UNIVERSIDADE, VALORIZANDO A ESCOLA E DESENVOLVENDO A COMUNIDADE
}

\author{
Clayton dos Santos Silva ${ }^{1 *}$, Romário Guimarães Verçosa de Araúijo ${ }^{1}$, Aleska Batista da Silva ${ }^{1}$, Gessyca Thays dos \\ Santos Silva1, Erilvado James Rocha do Rego', Felipe dos Anjos Cardoso ${ }^{1}$, Abel Washington de Albuquerque ${ }^{2}$, \\ Jessé Rafael Bento de Lima'.
}

\author{
${ }^{1}$ Estudante de Graduação em Agronomia, Centro de Ciências Agrárias (CECA), Universidade Federal de Alagoas (UFAL), BR 104 \\ Norte, Km 85, Rio Largo, AL. CEP 57.000-100. \\ 2Professor, Centro de Ciências Agrárias (CECA), Universidade Federal de Alagoas (UFAL), BR 104 Norte, Km 85, Rio Largo, AL. CEP \\ 57.000-100. \\ Autor para correspondência: Clayton dos Santos Silva; clayton@live.com.pt
}

RESUMO: 0 presente trabalho objetivou sensibilizar os alunos para práticas voltadas ao meio ambiente, alimentação saudável e formação social, na Escola de Ensino Fundamental Dr. Gastão Oiticica, Rio Largo, Alagoas. A metodologia para execução consistiu na escolha do local, capacitação, preparo de canteiros, semeadura e manutenção da horta. Após o manejo da horta os alunos desenvolveram atividades educativas que vieram confirmar o processo de aprendizagem. A horta permitiu o desenvolvimento de valores sociais e ambientais além de favorecer no desenvolvimento cognitivo dos alunos. Justifica-se a necessidade da elaboração e desenvolvimento desta atividade, com a implantação da horta como um espaço educador sustentável, que estimule a incorporação, a percepção e a valorização da dimensão educativa a partir do meio ambiente, bem como produtora de aprendizagens múltiplas e significativas buscando através de metodologias diferenciadas despertarem nos educandos o interesse pelo conhecimento, bem como uma melhor interação do aluno com a disciplina em sala de aula e a comunidade, potencializando as aprendizagens significativas. Com os dados obtidos pode-se concluir que a horta é de grande importância para a escola tanto na economia como ter alimentos saudáveis nas refeições das crianças.

PALAVRAS-CHAVE: Horta, Escola, Comunidade, Extensão

\section{SCHOOL HORTA: THE EXTENSION DIALOGGING WITH THE UNIVERSITY, VALUING THE SCHOOL AND DEVELOPING THE COMMUNITY}

\begin{abstract}
The present work aimed to sensitize the students to practices focused on the environment, healthy eating and social formation, at Dr. Gastão Oiticica Elementary School, Rio Largo, Alagoas. The methodology for implementation consisted in the selection of the site, training, preparation of beds, sowing and maintenance of the garden. After the management of the garden the students developed educational activities that came to confirm the learning process. The garden allowed the development of social and environmental values besides favoring the students' cognitive development. It is necessary to elaborate and develop this activity, with the implementation of the garden as a sustainable educational space, which stimulates the incorporation, perception and appreciation of the educational dimension from the environment, as well as producing multiple and meaningful learning Seeking through different methodologies to awaken in the students the interest for knowledge, as well as a better interaction of the student with the discipline in the classroom and the community, enhancing the significant learning. With the data obtained one can conclude that the vegetable garden is of great importance for the school both in the economy and to have healthy foods in the children's meals.
\end{abstract}

KEYWORDS: Garden, School, Community, Student 


\section{INTRODUÇÃO}

A necessidade de aumentar a produção de alimentos no mundo se deu devido ao crescimento populacional nas ultimas décadas, e aliado a esse crescimento, o cuidado com a saúde humana e 0 bem estar animal. Nesse contexto, a preocupação em produzir alimentos saudáveis e de boa qualidade, ao mesmo tempo preservando o meio ambiente, se tornou essencial para o equilíbrio ecológico, sendo assim, a educação ambiental se tornou uma ferramenta fundamental para conscientização e transformação da sociedade como um todo.

A prática da horticultura escolar tornou-se um grande aliado no ensino, na construção e na conscientização de valores agroecológicos para crianças e adolescentes de todo o país. Um laboratório vivo, onde minúsculas sementes se tornam vultuosas plantas, onde belas flores rompem a barreira do solo e se mostram belas e imponentes, atiçando assim a curiosidade do aluno, instigando o mesmo a conhecer e descobrir um mundo novo.

O intuito de desenvolver este projeto na escola em uma Escola de Ensino Fundamental visa promover mudanças de valores, hábitos e mudanças de atitudes com plantio da horta e por meio da educação ambiental usando a sensibilização com a participação dos alunos e da comunidade circunvizinha.

0 desenvolvimento de projetos com esta finalidade tem grande impacto, devido a sua grande importância para os acadêmicos. Com ele pode-se colocar em prática a teoria aprendida no curso de agronomia do Centro de ciências agrárias da UFAL (Universidade Federal de Alagoas).

\section{MATERIAL E MÉTODOS}

O projeto foi desenvolvido na Escola de Ensino Fundamental Dr. Gastão Oiticica, situada no estado de Alagoas, município de Rio Largo, bairro da Mata do Rolo, que segundo dados de 2014, conta com uma estrutura física composta por: 9 salas de aula, 5 banheiros, 1 hall, 1 sala de direção e secretaria, 1 sala de lanche para os professores e alunos, 1 cozinha, 1 depósito para alimentos. Quanto ao corpo técnico, a escola conta com 41 funcionários. Atualmente, a escola abriga 516 crianças de 0 a 14 anos, dividas em 9 grupos, de acordo com a faixa etária. Sendo que essas crianças permanecem na unidade no período (das $8 \mathrm{~h}$ às $12 \mathrm{~h}$ e das $14 \mathrm{~h}$ às $18 \mathrm{~h}$ ) e provém de diversas comunidades do bairro Mata do Rolo.

0 projeto foi idealizado por acadêmicos do curso de Agronomia, do Centro de Ciências Agrárias - CECA, unidade acadêmica vinculada a Universidade Federal de Alagoas - UFAL.

Foram realizadas, em parceria com professores e funcionários da instituição, palestras ministradas pelos acadêmicos de agronomia com os alunos da escola, para conhecerem e desmistificarem eventuais dúvidas sobre o projeto e área de atuação, abordando assuntos como, preservação do meio ambiente e da escola, importância de uma alimentação saudável e a importância da não utilização de produtos químicos na produção alimentar.

Em aula ministrada pelos próprios professores foram ensinados conceitos básicos de botânicas: raízes, caule, folhas, flores, frutos e sementes, para um melhor entendimento sobre a Morfologia Vegetal.

A instituição disponibilizou uma área de 70 $\mathrm{m}$, onde foi utilizado inicialmente apenas $20 \mathrm{~m}, 0$ terreno foi limpo pelos estudantes com o auxilio de Enxadas, Ciscadores, Pás, Lixeiros para recolhimento de todo o lixo jogado anteriormente pelos alunos da escola, para o início do projeto. Para o plantio foram levantados dois canteiros para produção de alface, tomate, pimentão e coentro e um leirão para produção de repolho e cebolinha. Para esse processo foram utilizadas pás, ciscadores, enxadas e regadores. Após o plantio das sementes os canteiros e o leirão foi coberto com cobertura morta retirada através do próprio terreno, como folhas de bananeiras e a vegetação retirada do local.

A manutenção da Horta foi feita através das crianças com acompanhamento dos professores e dos graduandos envolvidos. A irrigação foi feita durante os horários da manhã, em torno das $8 \mathrm{~h}$ e no final da tarde às $17 \mathrm{~h}$. Nos finais de semana a irrigação era feita pelos funcionários da escola.

\section{RESULTADOS E DISCUSSÃO}

Após a implementação do projeto de extensão na Escola de Ensino Fundamental Dr. Gastão Oiticica, houve uma perceptível melhora no rendimento escolar, como também no comportamento e interação dos alunos e a preocupação com o meio ambiente. 
Através desse projeto foi possível disseminar alguns valores ambientais e agroecológicos no corpo social local e escolar, onde após a colheita foi feita uma feira de amostra entre os pais, alunos e a população, onde os próprios aprendizes envolvidos na horta explicaram a importância da produção orgânica e as etapas do projeto até a sua conclusão, o que aproximou ainda mais os moradores a escola e pôde aprimorar o conhecimento em agroecologia de todos envolvidos. Este projeto também tornou possível aproximação da Universidade com a comunidade, proporcionando a troca de conhecimento entre academia e a comunidade local.

O desenvolvimento desse projeto horta escolar, com plantio de hortaliças contribuiu para o consumo de alimentos saudáveis dos alunos previstos pelos órgãos legais, e que não são vistas com frequência nas escolas circunvizinhas.

Existem programas que contribuem na inserção da alimentação na escola, como por exemplo, o Programa Nacional de Alimentação Escolar - PNAE dispõe da gestão da alimentação escolar, do Conselho de Alimentação Escolar, das cantinas e cozinhas nas escolas e o trabalho dos nutricionistas e da educadora na escola (BRASIL, 2010).

Dessa forma, por mais que seja incentivada a alimentação, a maioria das cantinas são pequenas, continuando na prática repleta de alimentos pobres em vitaminas, como salgados industrializados ou fritos, os campeões de consumo pelos estudantes.

A qualidade e diversidade da merenda escolar ampliaram, pois parte dos alunos implantou uma horta em casa melhorando a alimentação e a qualidade de vida, a consciência ambiental dos alunos se aprimorou. E isso trouxe mais a participação dos familiares nesse projeto, que deixou de ser um projeto só de enfoque escolar mais também de âmbito comunitário.

Os pais participam mais e muitos deles chegam a pedir sementes e raízes para poder plantar em seus quintais. Muitas vezes esses pedidos são feitos por exigência dos próprios filhos, por tanto se envolver em seu dia-dia na escola. Além do aspecto nutricional, este projeto, vem desenvolvendo: aspectos crítico das pessoas, de conhecimento ambiental e de valores econômicos.
Desta forma, é importante ressaltar que, entre a alimentação adequada, sua aceitação e 0 entendimento de que esta é a melhor opção, há uma grande distância que certamente é diminuída quando a criança tem a oportunidade de acompanhar 0 desenvolvimento do próprio alimento. Os resultados e objetivos traçados foram positivos, pois trabalhar com crianças permite um aproveitamento grande, pois elas se entregam ao conhecimento e busca aprender sempre mais. A horta pôde proporcionar uma boa rentabilidade, pois se obteve pouca perda com ataque de praga onde aplicamos controle de pragas natural sem veneno (utilizou-se o fumo com um resultado bom). Dos colaboradores houve aprendizado e expectativa de continuidade do projeto horta com alunos da escola, implementando o plantio mais variedades de hortaliças e até mesmo leguminosas.

A horta implantada não teve retorno financeiro, uma vez que sua produção foi toda destinada à merenda das crianças, porém o que se conseguiu conquistar através deste projeto foi a promoção da valorização do meio ambiente visando sustentabilidade e economia, e a possibilidade do aprendizado sem valor comercial. Desta forma, o beneficio buscado através deste projeto horta escola é intangível, além do aprendizado pessoal, mostrou benefícios sociais dentro dos pilares da sustentabilidade, entendendo que o uso desenfreado de hoje é a falta de recursos naturais amanhã.

A inserção da horta é de suma importância para comunidade escolar atuando na aprendizagem de todos envolvidos e formando futuros cidadãos, com aplicações de varias atividades pedagógicas que contribuem para a formação no aspecto social, econômica e ambiental, como também, a horta escolar proporciona perspectivas melhores no aspecto campocidade uma vez que aproxima a cidade do campo ampliando assim a qualidade de vida.

Com a proposta implantada na escola obtiveram-se ganhos positivos com resultados esperados alcançados, através de mudanças alimentares e consumo diário pelos alunos e de pais que relataram que passaram a consumir hortaliças devido às cobranças dos filhos. Portanto, é notório que a horta contribui para um ensino e aprendizagem, tanto para inserção ao consumo das hortaliças como para uma consciência ambiental e sustentável. 


\section{AGRADECIMENTOS}

Agradecemos primeiramente a Escola, por acreditar nesse projeto e nos ajudar em tudo que precisamos. Agradecemos aos professores pela dedicação e pelo empenho, e agradecemos aos nossos queridos alunos, pela oportunidade de passarmos todo o nosso conhecimento e para eles, e ao mesmo tempo, aprendermos com as crianças.

Agradecemos a nossa Universidade por nos capacitar e nos apoiar nessa grande jornada.

Agradecemos a todos sonham, como nós, que uma sociedade justa e igualitária para todos é sim possível.

\section{REFERÊNCIAS BIBILOGRÁFICAS}

http://guiaalagoas.escolasecreches.com.br/ comunicacao-e-uso-de-midias/ESCOLA-EFDOUTOR-GASTAO-OITICICA-rio-largo-rio-largoalagoas-i27040500.htm, acessado no dia 15 de março de 2017.

http://www.rebrae.com.br/experiencias/A_horta_ escolar.pdf. Acessado no dia 15 de março de 2017. http://educador.brasilescola.com/estrategias-ensino/ construindo-uma-horta-na-escola.htm. Acessado no dia 15 de março de 2017.

BRASIL, Ministério do Meio Ambiente e Ministério da Educação. Programa Nacional de Educação Ambiental. MMA/MEC, 1999. BRASIL, Fundo Nacional de Desenvolvimento da Educação.

Programa Nacional de Alimentação Escolar. Disponível em: http://www.portaltransparencia.gov.br/ aprendaMais/documentos/curso_PNAE.pdf. Acesso em: 15 de maio de 2017.

CECANE PARANÁ. A agricultura familiar e o programa nacional de alimentação escolar - PNAE. Curitiba, 2010.

SELEÇOES, do Reader's Digest. CURANDO AS DOENÇAS DO DIA-A-DIA: Métodos Naturais. $1^{\text {a }}$ Edição, dezembro 2002, 190-250. 